\section{Two Faces of LRBA Deficiency in Siblings: Hypogammaglobulinemia and Normal Immunoglobulin Levels}

Azizi $\mathrm{G}^{1,2}$, Abolhassani $\mathrm{H}^{2,3,4}$, Habibi $\mathrm{S}^{2,3}$, Rahamooz $\mathrm{T}^{2}$, Mohammadi $\mathrm{H}^{5}$, Jafarnezhad-Ansariha $\mathrm{F}^{6}$, Mortazavi-jahromi $\mathrm{SS}^{6}$, Yazdani $\mathrm{R}^{2}$, Aghamohammadi A A $^{2,3 *}$

${ }^{I}$ Non-Communicable Diseases Research Center, Alborz University of Medical Sciences, Karaj, Iran; and Department of Laboratory Medicine, Imam Hassan Mojtaba Hospital, Alborz University of Medical Sciences, Karaj, Iran

${ }^{2}$ Research Center for Immunodeficiencies, Children's Medical Center, Tehran University of Medical Sciences, Tehran, Iran

${ }^{3}$ Primary Immunodeficiency Diseases Network (PIDNet), Universal Scientific Education and Research Network (USERN), Tehran, Iran

${ }^{4}$ Division of Clinical Immunology, Department of Laboratory Medicine, Karolinska Institute at Karolinska University Hospital Huddinge, Stockholm, Sweden

${ }^{5}$ Department of Immunology, School of Medicine, Tabriz University of Medical Sciences, Tabriz, Iran

${ }^{6}$ Department of Immunology, School of Public Health, Tehran University of Medical Sciences, Tehran, Iran

J Investig Allergol Clin Immunol 2018; Vol. 28(1): 48-50 doi: $10.18176 /$ jiaci.0205

Key words: LRBA. Hypogammaglobulinemia. Immunoglobulin.

Palabras clave: LRBA. Hipogammaglobulinemia. Inmunoglobulina.

LPS-responsive beige-like anchor protein (LRBA) deficiency is a novel primary immunodeficiency disorder (PID) caused by biallelic mutations in the $L R B A$ gene that abolish its protein expression [1]. Similar to common variable immune deficiency, immune dysregulation as a consequence of LRBA deficiency leads to recurrent infections, autoimmunity, and enteropathy [1-7]. Affected individuals mainly show reduced levels of at least 2 Ig isotypes. We report on siblings from 2 different families with LRBA deficiency who were carrying the same mutation but had discordant serum Ig levels. Clinically, in both families, one sibling had hypogammaglobulinemia, whereas the other had normal Ig levels. Next-generation sequencing is a useful approach for molecular diagnosis of human diseases. The increasing availability of targeted next-generation sequencing panels, whole exome sequencing (WES), and whole genome sequencing, have facilitated identification of genetic defects in PID patients with the same mutation and variable clinical phenotypes [8].

\section{Family 1}

Patient 1 was the child of first cousins. At 3 years of age, she presented with growth retardation, upper respiratory tract infection, recurrent pneumonia, recurrent diarrhea, and hepatosplenomegaly. She was diagnosed with probable IgA deficiency (Table). At age 8, she developed autoimmune thyroiditis, and at age 13 she was diagnosed with bronchial asthma, atopic dermatitis, mucosal candidiasis, and refractory diarrhea. Laboratory evaluation revealed immune thrombocytopenia purpura and low serum Ig levels, indicating progression from IgA deficiency to hypogammaglobulinemia. Intravenous immunoglobulin (IVIG) therapy was started. She later developed autoimmune hemolytic anemia and underwent splenectomy at age 20 owing to hypersplenism. The patient also lost bone mineral density during the previous year and developed bronchiectasis. Gastrointestinal biopsy revealed chronic active gastritis-esophagitis and atrophic duodenal mucosa (villous atrophy). WES revealed a splice site mutation (c. $4729+2$ dupT) in the LRBA gene.

Patient 2 was a 20-year-old woman and sibling of patient 1 who developed autoimmune hemolytic anemia at 5 years of age. She also had upper respiratory tract infections and generalized lymphadenopathy and splenomegaly. Persistence of her anemia necessitated splenectomy at that time. She experienced severe viral meningitis at age 10 . The immunological evaluation showed increased doublenegative T-cell counts, low $\mathrm{CD} 8^{+} \mathrm{T}$-cell counts, and normal Ig levels. She developed immune thrombocytopenia purpura at age 11 and another episode of viral meningitis at age 12. A granuloma-like lesion coupled with a demyelinating process in the brain was reported. Immunomodulatory therapy with high-dose IVIG was started 2 years later owing to loss of vision in her left eye. From the age of 15 until now, the patient has had multiple episodes of sinusitis and otitis media. She also has low bone mineral density. Mutation analysis revealed the same mutation as her sister.

\section{Family 2}

Patient 3 , the index case in family 2 , was a 27 -year-old man born to consanguineous parents. Symptoms first appeared at age 2 years, with respiratory tract infection. At age 10 , he was diagnosed with hypogammaglobulinemia. His clinical records included several episodes of pneumonia, sinusitis, and chronic diarrhea. Other reported manifestations were arthritis, bronchiectasis, failure to thrive, and finger clubbing. Loss of bone mineral density and Helicobacter pylori infection were also detected. This patient was initially diagnosed with IgA deficiency, although further investigations revealed hypogammaglobulinemia and absent isohemagglutinins. IVIG therapy was started. WES analysis revealed a homozygous nonsense mutation (c.C4814G [p.S1605X, exon 30]), which was confirmed by Sanger sequencing.

Patient 4, the older brother of patient 3, was a 36-yearold man who had chronic sinusitis with no significant complications of immunodeficiency. The immunological evaluation revealed normal serum Ig and a specific antibody response to the vaccine. Lymphocyte subsets were also in the normal range. WES analysis revealed a homozygous nonsense mutation in the LRBA gene similar to that of his younger brother. Western blot analysis of both patients revealed absent LRBA expression.

Mutations affecting different domains of LRBA result in diminished expression and a spectrum of clinical phenotypes that includes hypogammaglobulinemia, enteropathy, autoimmune disorders, respiratory infections, 
Table. Immunologic Characteristics of Patients With LRBA Deficiency

\begin{tabular}{|c|c|c|c|c|c|}
\hline Parameters & Patient 1 & Patient 2 & Patient 3 & Patient 4 & Normal Range \\
\hline $\mathrm{IgG}, \mathrm{mg} / \mathrm{dL}^{\mathrm{a}}$ & 765 & 1207 & 360 & 1237 & $503-1719$ \\
\hline $\operatorname{IgG} 1, \mathrm{mg} / \mathrm{dL}^{\mathrm{a}}$ & 480 & NA & 236 & NA & $280-1030$ \\
\hline $\operatorname{IgG} 2, \mathrm{mg} / \mathrm{dL}^{\mathrm{a}}$ & 72 & NA & 31 & NA & $66-502$ \\
\hline $\operatorname{IgG} 3, \mathrm{mg} / \mathrm{dL}^{\mathrm{a}}$ & 163 & NA & 40 & NA & $11.5-106$ \\
\hline $\mathrm{IgG} 4, \mathrm{mg} / \mathrm{dL}^{\mathrm{a}}$ & 41 & NA & 0.8 & NA & $1.0-121$ \\
\hline $\operatorname{IgM}, \mathrm{mg} / \mathrm{dL}^{\mathrm{a}}$ & 69 & 17 & 44 & 121 & $34-255$ \\
\hline $\operatorname{IgA}, \mathrm{mg} / \mathrm{dL}^{\mathrm{a}}$ & 5 & 67 & 0 & 255 & $86-320$ \\
\hline $\operatorname{IgE}, \mathrm{IU} / \mathrm{mL}^{\mathrm{a}}$ & 0.3 & 0 & NA & 1 & $<46$ \\
\hline Specific antibody response ${ }^{a}$ & Positive & Positive & Negative & Positive & Positive \\
\hline White blood cell count, cell $/ \mu \mathrm{L}^{\mathrm{a}}$ & 8730 & 3300 & 14400 & 6030 & $4000-11000$ \\
\hline Lymphocytes, cell $/ \mu \mathrm{L}^{\mathrm{a}}$ & 2095 & 2145 & 2016 & 2412 & $1000-5300$ \\
\hline $\mathrm{CD}^{+}$, cell $/ \mu \mathrm{L}^{\mathrm{a}}$ & 1739 & 1625 & 1492 & 1761 & $800-3500$ \\
\hline $\mathrm{CD}^{+}$, cell $/ \mu \mathrm{L}^{\mathrm{a}}$ & 649 & 643 & 363 & 769 & $400-2100$ \\
\hline $\mathrm{CD} 8^{+}$, cell $/ \mu \mathrm{L}^{\mathrm{a}}$ & 670 & 558 & 1109 & 1066 & $200-1200$ \\
\hline $\mathrm{CD} 16-56^{+}$, cell $/ \mu \mathrm{L}^{\mathrm{a}}$ & 98 & & 201 & NA & $70-1200$ \\
\hline $\mathrm{CD} 19^{+}$, cell $/ \mu \mathrm{L}^{\mathrm{a}}$ & 147 & 493 & 121 & 193 & $200-600$ \\
\hline Transitional, $\%$ of B lymphocytes & 0.7 & 0 & 0 & NA & $3-5.9$ \\
\hline Naïve, \% of B lymphocytes & 50 & 32 & 55 & NA & $65.6-79.6$ \\
\hline Marginal zone, $\%$ of B lymphocytes & 0 & 0 & 0 & NA & 7.4-13.9 \\
\hline Switched memory, $\%$ of B lymphocytes & 3.6 & 2.1 & 4.1 & NA & $7.2-12.7$ \\
\hline Plasmablasts, $\%$ of B lymphocytes & 0 & 0 & 0 & NA & $0.6-1.6$ \\
\hline CD2 $21^{\text {low }}, \%$ of B lymphocytes) & 45 & 65 & 36 & NA & $0.9-3.6$ \\
\hline Regulatory T-cells, $\%$ of $\mathrm{CD}^{+}{ }^{+} \mathrm{T}$ cells & 0.17 & 0.1 & 1.1 & 2.8 & $1.2-3.1$ \\
\hline Hemoglobin, g/dL & 7 & 4.6 & 13 & 13 & $12-16$ \\
\hline Platelet, $\times 10^{3}$ & 226 & 458 & 182 & 138 & $150-400$ \\
\hline IgG anti-IgA antibody & 2.3 & NA & 1.2 & NA & Negative \\
\hline Thyroid peroxidase antibody, IU/mL & 535 & NA & NA & NA & $<35$ \\
\hline Thyroglobulin antibody, IU/mL & $>5000$ & NA & NA & NA & $<20$ \\
\hline Direct Coombs test & Positive & Positive & NA & NA & Negative \\
\hline Indirect Coombs test & Positive & NA & NA & NA & Negative \\
\hline
\end{tabular}

Abbreviation: NA, not available.

avalues were obtained at the time of diagnosis of immunodeficiency.

and combinations of these phenotypes. There is no apparent genotype-phenotype correlation, as patients with the same mutation in $L R B A$ may present different clinical phenotypes or even be asymptomatic [8]. Incomplete penetrance was reported in 3 Palestinian brothers with the same variation in $L R B A, 2$ of whom had organomegaly and autoimmune disease, while another was symptom-free [8]. We report 2 immunologic phenotypes of LRBA deficiency in 2 female siblings, including hypogammaglobulinemia and normal Ig levels with autoimmunity. Moreover, we report 2 male siblings with LRBA deficiency with the same mutation and discordant clinical and immunological presentations. The index patient had severe clinical complications, including chronic diarrhea, organomegaly, respiratory tract infection, and hypogammaglobulinemia, whereas his brother had no clinical complications and normal serum Ig and specific antibody levels.

Therefore, our findings are consistent with those of a report confirming that the same genetic mutation in the $L R B A$ gene can manifest with a broad phenotypic spectrum and no genotype-phenotype correlation. In most cases where a particular genotype is inherited, it is not fully known why the same allele can cause subtle or profound differences in phenotypes. A disease phenotype may be modulated by genetic 
and nongenetic modifiers, including modifier genes, allelic variation, environmental factors, and complex genetic and environmental interactions. In some cases, there is genetic evidence that modifier genes influence phenotypic variation. The correlation between genotype and phenotype is a statistical relationship that predicts a physiological trait in a healthy individual or an abnormality in a patient with a given mutation or a group of similar mutations. Modifier genes can affect penetrance, dominance, and expressivity. A genetic modifier, when expressed, is able to alter the expression of another gene. Modifier genes can affect transcription and alter immediate gene transcript expression, or they can affect phenotypes at the cellular or organismal level $[9,10]$. Further studies are required to define the exact role of genetic and nongenetic parameters in the penetrance of LRBA deficiency.

\section{Funding}

The authors declare that no funding was received for the present study.

\section{Conflicts of Interest}

The authors declare that they have no conflicts of interest.

\section{References}

1. Azizi G, Abolhassani H, Mahdaviani S, Chavoshzadeh Z, Eshghi P, Yazdani R, et al. Clinical, Immunological, Molecular Analyses and Outcomes of Iranian Patients with LRBA Deficiency: A Longitudinal Study. Pediatr Allergy Immunol. 2017;28:478-84.

2. Azizi G, Abolhassani H, Asgardoon MH, Alinia T, Yazdani $R_{\iota}$ Mohammadi J, et al. Autoimmunity in common variable immunodeficiency: epidemiology, pathophysiology and management. Expert Rev Clin Immunol. 2017;13:101-15.

3. Yazdani $R$, Abolhassani $H$, Asgardoon M, Shaghaghi $M$, Modaresi M, Azizi G, et al. Infectious and Non-Infectious Pulmonary Complications in Primary Immunodeficiencies. J Investig Allergol Clin Immunol. 2017;27:213-24.

4. Azizi G, Rezaei N, Kiaee F, Tavakolinia N, Yazdani R, Mirshafiey A, et al. T-Cell Abnormalities in Common Variable Immunodeficiency. J Investig Allergol Clin Immunol. 2016;26:233-43.

5. Yazdani R, Heydari A, Azizi G, Abolhassani H, Aghamohammadi A. Asthma and Allergic Diseases in a Selected Group of Patients With Common Variable Immunodeficiency. J Investig Allergol Clin Immunol. 2016;26:209-11.

6. Mohammadinejad P, Pourhamdi S, Abolhassani $H$, Mirminachi B, Havaei A, Masoom SN, et al. Primary Antibody Deficiency in a Tertiary Referral Hospital: A 30-Year Experiment. J Investig Allergol Clin Immunol. 2015;25:416-25.

7. Azizi G, Abolhassani H, Yazdani R, Mohammadikhajehdehi S, Parvaneh N, Negahdari B, et al. New therapeutic approach by sirolimus for enteropathy treatment in patients with LRBA deficiency. Eur Ann Allergy Clin Immunol. 2017:49:235-9.

8. Revel-Vilk S, Fischer U, Keller B, Nabhani S, Gamez-Diaz $L$, Rensing-Ehl $A$, et al. Autoimmune lymphoproliferative syndrome-like disease in patients with LRBA mutation. Clin Immunol. 2015;159:84-92.

9. Nadeau JH. Modifier genes in mice and humans. Nat Rev Genet. 2001;2:165-74.

10. Lobo I. Same Genetic Mutation, Different Genetic Disease Phenotype. Nature Education. 2008;1:64.

Manuscript received June 16, 2017; accepted for publication October 14, 2017

Asghar Aghamohammadi Children's Medical Center Hospital 62 Qarib St., Keshavarz Blvd., Tehran 14194, Iran E-mail: aghamohammadi@tums.ac.ir 